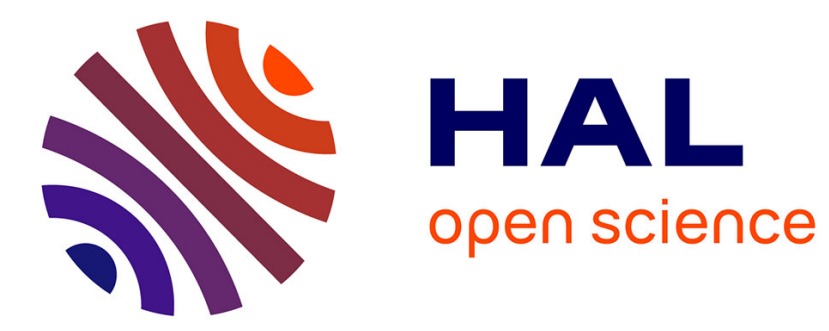

\title{
E-Government Research Domain: Comparing the International and Russian Research Agenda
}

Yury Kabanov, Andrei V. Chugunov, Boris Nizomutdinov

\section{To cite this version:}

Yury Kabanov, Andrei V. Chugunov, Boris Nizomutdinov. E-Government Research Domain: Comparing the International and Russian Research Agenda. 18th International Conference on Electronic Government (EGOV), Sep 2019, San Benedetto del Tronto, Italy. pp.18-30, 10.1007/978-3-030-273255_2. hal-02445805

\author{
HAL Id: hal-02445805 \\ https://hal.inria.fr/hal-02445805
}

Submitted on 20 Jan 2020

HAL is a multi-disciplinary open access archive for the deposit and dissemination of scientific research documents, whether they are published or not. The documents may come from teaching and research institutions in France or abroad, or from public or private research centers.
L'archive ouverte pluridisciplinaire HAL, est destinée au dépôt et à la diffusion de documents scientifiques de niveau recherche, publiés ou non, émanant des établissements d'enseignement et de recherche français ou étrangers, des laboratoires publics ou privés. 


\title{
E-Government Research Domain: Comparing the International and Russian Research Agenda
}

\author{
Yury Kabanov, ${ }^{1,2}{ }^{凶}$ Andrei V. Chugunov ${ }^{1}$ and Boris Nizomutdinov ${ }^{1}$ \\ ${ }^{1}$ ITMO University, St. Petersburg, Russia \\ ${ }^{2}$ National Research University Higher School of Economics, St. Petersburg, Russia \\ ykabanov@hse.ru; chugunov@corp.ifmo.ru, boris-wels@yandex.ru
}

\begin{abstract}
Positioning e-government as a discipline is a matter of continuous discussion, and it remains topical to estimate its conceptual integrity and explore the interconnection between the main research contexts, especially due to the emergence of new areas like e-participation. The analysis of the national research programs and their comparison to the global agenda is also becoming more salient. Addressing these two issues by means of a scientometrics approach, we explore the extended e-government domain on the global scale and in the Russian Federation. Findings suggest that the global e-government represents a coherent field, although further integration between research contexts is important. At the same time, the Russian e-government research is lagging behind, due to low internationalization and few stimuli for knowledge production.
\end{abstract}

Keywords: E-Government, E-Participation, E-Democracy, Scientometrics

\section{Introduction}

The shape of e-government as a discipline is a matter of continuous discussions. Scholars emphasize its fragmentation due to the diversified researchers' background [23] or the overall discipline immaturity [25]. While further specialization has led to the emergence of the new, relatively independent areas, like e-participation [28], the field may benefit from this variety, as put by Scholl, if "developing into an integrative science with multi-, inter-, and transdisciplinary characteristics" [32, p. 35]. It calls for further analysis of the research domain, its conceptual structure, integrity and interdisciplinarity, when taken along with e-participation and e-democracy areas.

At the same time, it is no less important to contrast the global research agenda with the national patterns of knowledge production, which are usually "under the radar" of the international academia, despite the growing interest in this subject $[6 ; 8 ; 10]$. Such analysis is helpful in formulating steps forward for national research, and to asses the e-government research domain in a more complex way.

The goal of this paper is hence twofold: first, to overview the extended egovernment domain in order to reveal the major research contexts, their interconnections and dynamics. Secondly, to compare them to the national agenda of egovernment studies, taking Russia as a case. The study employs a scientometrics 
analysis based on keyword co-occurrence. The structure of the paper is as follows. First, we overview the background literature on how scientometrics complements literature reviews in understanding e-government. Secondly, we present the methods and data we use. Empirical findings are described in the fourth and fifth sections, followed by a discussion of the results, limitations and possible steps forward.

\section{Background}

Systematic literature review is a demanding genre in e-government, aiming at assessing the maturity of the discipline [25], pointing out pitfalls [14; 37] and providing methodological coherence [23]. For e-participation, literature systematization [20; 21; 28 ; 33] became vital in establishing the field identity. As the research volume expands, more focused reviews emerge, introducing emerging topics $[1 ; 13 ; 22]$, reviewing particular outlets $[9 ; 12]$ or surveying scholars on their new topics of interest [31]. Along with thematic and institutional angles, the geographical one is getting salience, where scholars evaluate local dynamics of knowledge production and discuss problems of internationalization $[6 ; 8 ; 10 ; 11]$. Despite their indisputable value, literature reviews are often criticized for their possible bias and errors in literature selection [27; 38], and here scientometrics tools seem a promising alternative, and their usage is now quite regular in e-government. There have been several attempts to run such analysis using various software, search queries and databases, mostly focusing on analyzing hotspots and emerging topics, and assessing the multidisciplinary and international nature of knowledge production.

The identification of trends depends on the timespan and technique employed. For instance, Cheng and Ding found 5 core themes in e-government research: (1) egovernment development; (2) e-government evolution; (3) user research; (4) information storage and (5) standards and specification, with the emerging topic of performance evaluation [4]. The analysis by Jalali revealed that the trend in egovernment is towards the analysis of openness, media, cloud services and participation [16]. For e-participation, the analysis by Qi et. al. emphasized the increasing focus on democracy and social media [24].

A more nuanced analysis for both e-government and e-participation was presented by Alcaide-Muñoz et al. with SciMAT to build co-word networks and analyze the temporal dynamics $[2 ; 27]$. In the case of e-government they studied several subperiods, identifying emerging, fading and established co-word clusters. The temporal evolution is justified by the set of concepts emerging (e.g. "social media" and "smart city") and fading (e.g. "administrative reform") overtime [2, p. 551]. In case of eparticipation, they found several research foci, e.g. techno-social, instrumental, contextual and technological and consider that there is an "evolution of this field of knowledge to a more techno-social system" [27, p. 118].

The issues of collaboration between countries, institutions and authors are analyzed by co-citation or co-authorship analysis. Studies usually emphasize the low level of cooperation between authors and institutions, the gaps between developed and developing countries and the dominance of the US institutions in knowledge production 
[17]. While multidisciplinary dimensions seem evident, the interdisciplinary nature of the e-government domain (as described by Scholl) [32] is questionable, as suggested by Hwang and Murphy [15]. A similar conclusion is implied in Bohman's analysis of how various technologies are portrayed in e-participation research, when scholars seem to neglect "relevant theories of technology from adjacent fields such as information systems, sociology of technology, or evolutionary economics" [3, p. 88].

While much has been done, some challenges and research gaps remain. First, although several scholars have successfully identified the front edges of e-government studies, few attempts have been made to overview and visualize the domain in its integrity. Hence, rather than defining the emerging topics, we aim at mapping the whole area, using the tool which has a clear advantage in visualizing science maps (the VOSviewer). Secondly, previous results are usually fuzzy due to the various research queries: here we believe e-government, e-governance, e-participation, and edemocracy should be taken as the core topics in the integral sample. It helps to avoid overexpansion of the domain, e.g. by including all various forms of online participation [19], and to grasp the identity of the research area (i.e. authors using such words associate themselves with it). Thirdly, there is a problem in publication selection: conferences are usually ignored, whilst they have proved their significance $[12 ; 31]$.

Fourthly, a clear research gap remains in terms of the multi- / interdisciplinary nature of e-government. It seems that standard tools are not very helpful (e.g. LNCS conference proceedings are usually related to Computer Science, while there can be issues from various disciplines). Rather, we suggest to look at the concepts used, how they can possibly relate to certain disciplinary dimensions, and then whether these concepts are shared by various disciplines or rather adhere to particular fields.

Finally, while previous literature suggests the importance of analyzing the national research agendas as well, still many cases remain under-explored. Although the recent article by Erzhenin [10] shed some light on some of the national e-government studies peculiarities (like their concentration on the Economics, Political Science and Law), this analysis employs a narrow definition of e-government and no network analysis is presented, so we hope to expand these findings both in scope and in methodology.

\section{$3 \quad$ Research Design}

Our scientometrics analysis is conducted using the VOSviewer software (http://www.vosviewer.com/), developed by van Eck and Waltman. Its key advantage is the interpretable visualization of bibliometric datasets [36], as science mapping "reflects the similarity of relatedness of the items as accurately as possible" [35, p. 5], giving more accurate results in normalization of co-occurrence [34], which is our main method. Co-occurrence helps to identify how often concepts are found together in various samples, thus helping to construct a conceptual map of the discipline.

For the analysis of the international and Russian research agenda we selected the Web of Science (WoS) database and eLIBRARY (https://elibrary.ru/) respectively. The analysis of the latter is challenging, as there is no automatic option to retrieve bibliographic data, so the information was gathered with a specifically developed parser. 
In both databases we employed the query: TS=("e-governance" OR "egovernance" $O R$ "electronic governance" OR "e-government" $O R$ "electronic government" $O R$ "egovernment" OR "e-participation" OR "electronic participation" OR "eparticipation" OR "e-democracy" OR "electronic democracy"). In the case of WoS we found 10,542 documents for 2000-2018 (most published in 2007-2018). Publications are almost equally distributed among journals and conference proceedings, and mostly in English. In $e L I B R A R Y, 23,000$ items were found, but some data (like publication year and citation) were missing due to technical reasons. Another limitation of $e L I B R A R Y$ is that it indexes much more publications, but usually at the expense of quality. Also, some publications are indexed by both databases, though the overlap is tiny.

With the VOSviewer we conducted a co-occurrence keyword analysis for both international and Russian databases, which estimated the intensity of one term usage with another. A special thesaurus (442 terms) was compiled to translate Russian terms into English, to combine similar keywords (e.g. "electronic services" and "e-services) and to eliminate possible typos. For the final analysis we took only the keywords occurring at least 15 times in the sample, deliberately excluding the query terms: they obviously occur in most publications and skew the analysis. Thus the final selection of keywords comprises of 364 terms for the international database and 281 terms for the Russian one. The properties of VOSviewer were set for better representations of results: co-occurrence based on full counting method, with association strength normalization technique (attraction - "1", repulsion - "0") [36]. We set 15 terms (10 for $e L I B R A R Y$ ) as a minimum to form clusters, which are then analyzed by looking at the combinations of keywords of which they comprise. In the visualizations (fig. 1 and fig. 3) the label size depicts its total link strength, while the width of links portrays the strength between two terms. Only links with the minimum strength of 30 are shown.

\section{$4 \quad$ Research Contexts in the International Agenda}

As expected, the e-government represents a vast array of research contexts (fig. 1). Based on the association strength between the keywords, five clusters were revealed. We refer them to as Infrastructure (green), Adoption (yellow), Management (blue), Participation (red) and Development (purple). Such labels were given in an attempt to cover the most widespread issues related to each of the clusters. Table 1 gives additional information, including the number of terms in each cluster and possible subtopics deduced from the keywords each cluster has. It should be noted that the list of such subtopics is not exclusive, and some clusters may overlap in addressing the same issue, and given mostly for a simplified reference to clusters.

Infrastructure cluster deals with how to create interoperable e-government information systems, set administrative workflows, provide usable and accessible services, thus also including public administration issues. It is rather disperse, falling into "hard" technical issues (like "interoperability" and "ontology"), administrative processes and questions of e-services' accommodation ("personalization”, "usability”), including "m-government". Here it is more connected to the second cluster - Adoption. The latter is explicitly empirical, quantitative and casual, tying e-government to 
e-commerce and using several dominating adoption models (like TAM and IS success models). The concept of trust in various applications is also of high interest here.

The Management cluster seems to cover aspects of public sector's tackling of innovations, digital transformations and organizational change. This involves, among other things, coordination of the interaction between different stakeholders, strategic management, intraorganizational changes and impact.

The largest cluster in the domain is Participation - a binary star system of edemocracy and e-participation, with a scope broad enough to disperse throughout other research contexts. It is more prone to public management when it comes to openness (e.g. open government data), and gets closer to Development and Adoption in questions of equality and inclusion. Its core topics are those connected to governance, citizens involvement and control, social media, local governments, as well as smartness (smart city and government) and co-creation. The most dispersed cluster is Development, covering important issues of adaptation and use of new technologies, their impact on developing countries in general and quality of institutions.

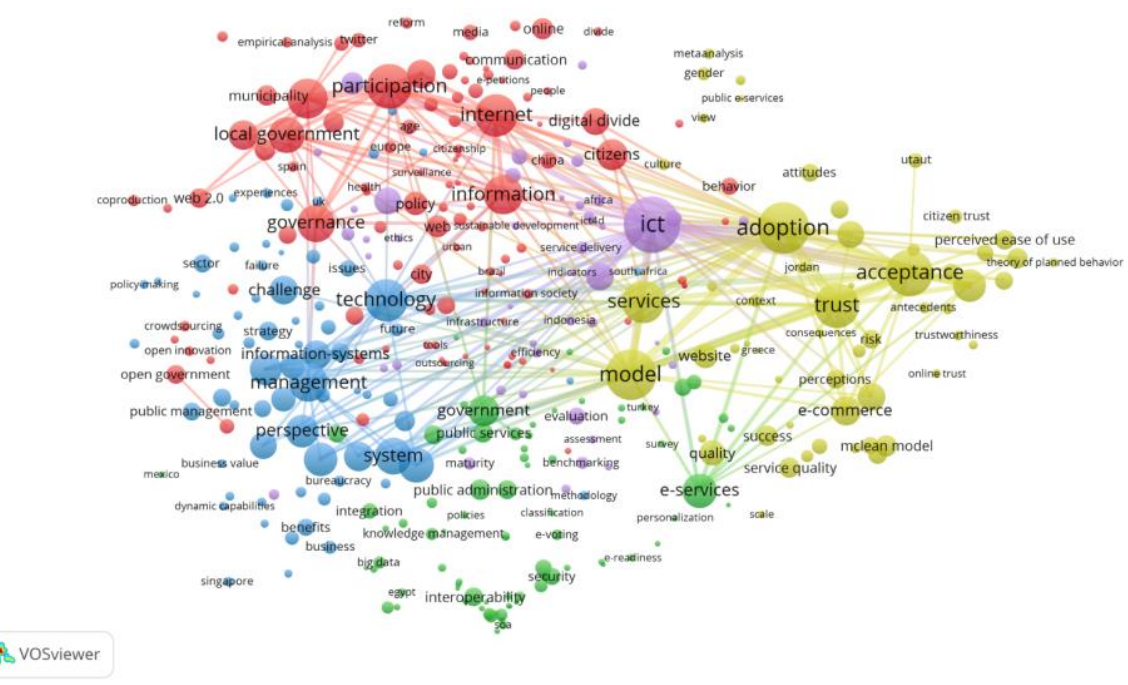

Fig. 1. Co-Occurrence Maps of Keywords in the International Agenda. Source: VOSviewer

In general, we may agree with Scholl, that the e-government domain "has already established itself as a multi-discipline endeavor spanning the full spectrum of hard and soft as well as pure and applied sciences" [32, p. 32]. The international research agenda indeed seems to have "harder" (e.g. Infrastructure) and "softer" (e.g. Participation) contexts, where all clusters play their role in understanding the phenomena: how e-tools are created, implemented and adapted, successfully accepted and utilized, and what role they might play in fostering citizens' involvement and human development. Yet we need to point out several peculiarities of the domain. First, as keyword analysis suggests, the hard - soft balance is shifted to a certain extent towards the latter, where it comes to the issues of participation and democracy, or at least to the 
interim hard-soft disciplines, as far as Management and Infrastructure are concerned. It may be another indication of the trend that e-government is becoming more citizenoriented [27], thus calling for the contribution from the Social Sciences field.

Secondly, though most concepts are linked to each other, the link strength between specific terms is rather weak. The clusters are mostly connected via more general anchor concepts like "ict", "internet", "services" but not on particular tools and applications where interdisciplinarity is of value. As an example, while "e-voting" is now more adjacent to Infrastructure, the research of this phenomenon can take advantage of "softer" insights as well. So does the concept of trust: while the need to study trust in e-participation was iterated a couple of years ago [29], there are few connections to Participation, in comparison to e-services.

Table 1. Clusters in E-Government International Research Agenda

\begin{tabular}{|c|c|c|c|}
\hline Cluster & $\begin{array}{l}\text { Number of } \\
\text { Keywords }\end{array}$ & Indicative Subtopics & Indicative Keywords \\
\hline \multirow[t]{6}{*}{$\begin{array}{l}\text { Infrastructure } \\
\text { (green) }\end{array}$} & \multirow[t]{6}{*}{86} & $\begin{array}{l}\text { E-Government Architec- } \\
\text { ture }\end{array}$ & $\begin{array}{l}\text { ontology, semantic web, linked data, cloud } \\
\text { computing }\end{array}$ \\
\hline & & Administrative Workflow & standardization, information sharing \\
\hline & & Security & privacy, authentication, e-signature \\
\hline & & E-Services & personalization, usability, accessibility \\
\hline & & Process Management & project management, business project \\
\hline & & Public Administration & public services, government \\
\hline \multirow[t]{4}{*}{$\begin{array}{l}\text { Adoption } \\
\text { (yellow) }\end{array}$} & \multirow[t]{4}{*}{56} & Factors of Adoption & $\begin{array}{l}\text { structural equation modeling, meta- } \\
\text { analysis }\end{array}$ \\
\hline & & Technology Acceptance & perceived usefulness, ease of use \\
\hline & & IS success model & service quality, information quality \\
\hline & & Trust & consumer trust, online trust \\
\hline \multirow{4}{*}{$\begin{array}{l}\text { Management } \\
\text { (blue) }\end{array}$} & \multirow[t]{4}{*}{68} & Interaction of Actors & bureaucracy, stakeholders, collaboration \\
\hline & & Strategic Management & innovations, implementation \\
\hline & & Intraorganizational & capabilities, leadership \\
\hline & & Impact & performance, public value \\
\hline \multirow{8}{*}{$\begin{array}{l}\text { Participation } \\
\text { (red) }\end{array}$} & \multirow[t]{8}{*}{106} & Openness & open government, open data \\
\hline & & Equality & inclusion, digital divide \\
\hline & & Governance & policy, decision making \\
\hline & & Citizen Involvement & deliberation, community \\
\hline & & Political Communication & media, elections \\
\hline & & Social Media & Facebook, twitter \\
\hline & & Public Control & accountability, transparency \\
\hline & & Local \& Smart & municipality, smart city \\
\hline \multirow{5}{*}{$\begin{array}{l}\text { Development } \\
\text { (purple) }\end{array}$} & \multirow[t]{5}{*}{48} & Adaptation and Use & ethics, diffusion \\
\hline & & Developing Countries & ICT4D, Africa, \\
\hline & & Productivity & sustainable development \\
\hline & & Institutional Quality & Good governance \\
\hline & & Evaluation & Benchmarking, assessment \\
\hline
\end{tabular}

Thirdly, though further research is needed, we may support earlier judgments that e-government is still a multi- rather than an interdisciplinary domain [15], and further integration is needed. This task is not an easy one, as the most internally cohesive clusters (that have strong internal links) - Participation and Adoption - appear to be rather independent from the others: the former is being institutionalized as eparticipation area, the latter is keeping coherence due to the limited number of theo- 
retical models (TAM, UTAUT, IS Success Model, etc.) and frequently used quantitative methods (surveys, structural equation modeling).

Another view on the same map is presented on fig. 2, where we present the overlay visualization based on the impact of each concept in the domain. The size of the item depicts the number of its occurrences in the sample, while the color represents its average normalized citation score: high (yellow), average (green) and low (blue). The map suggest that the issues covered in relatively more cited literature reside in Participation cluster (e.g. "social media", "government", "coproduction") and Adoption cluster (e.g. "technology acceptance model", "McLean model", "citizen trust"). Again it does not contradict earlier findings on emerging topics in e-government [2].

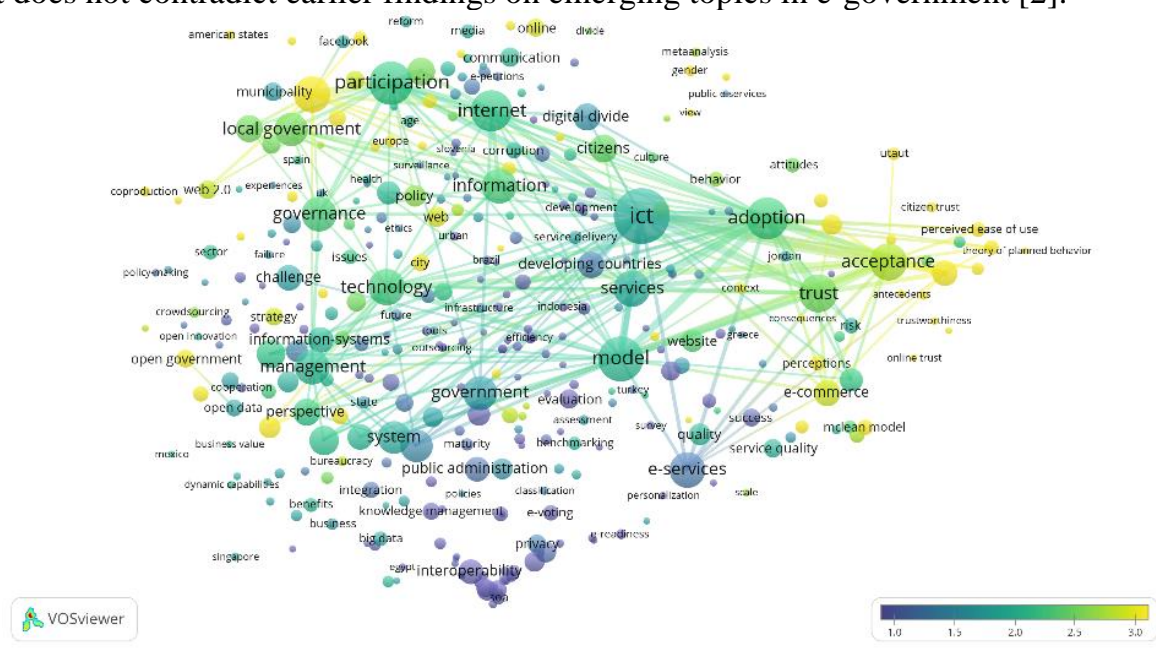

Fig. 2. Overlay Visualization by the Average Normalized Citation. Source: VOSviewer

\section{The Russian Research Agenda on E-Government}

The analysis of the Russian research agenda was technically limited due to the reasons described in section 3, so only the co-occurrence map is presented. Overall, 5 clusters were found, but the yellow and purple ones seem to be artifacts with $\mathrm{PhD}$ nomenclature terms. Others contain more meaningful and zoomed (fig. 3), we refer them to as: Public Services Provision (deep blue), ICT in Administration \& Economy (green), and Internet \& Politics (red).

Even though the number of publications analyzed is much higher as in the previous section, there are fewer terms and clusters extracted, and keywords grouping is not the same. Public Services Provision resembles to a certain extent Infrastructure in its emphasis on public services ("e-services", "service state") and bureaucracy informatization ("e-document", "e-signature"). Some global hot topics ("open government", "transparency") are also addressed here. ICT in Administration \& Economy has a topical overlap with Management in managerial ("transformation", "strategic planning") and performance ("effectiveness", "monitoring") issues, it also covers infrastructure ("optimization", "standardization") and recent trends towards digital econo- 
my ("cloud computing", "blockchain"). Internet \& Politics covers traditional topics of e-democracy ("e-voting") and e-participation ("public initiative"), but is largely focused on political communication.

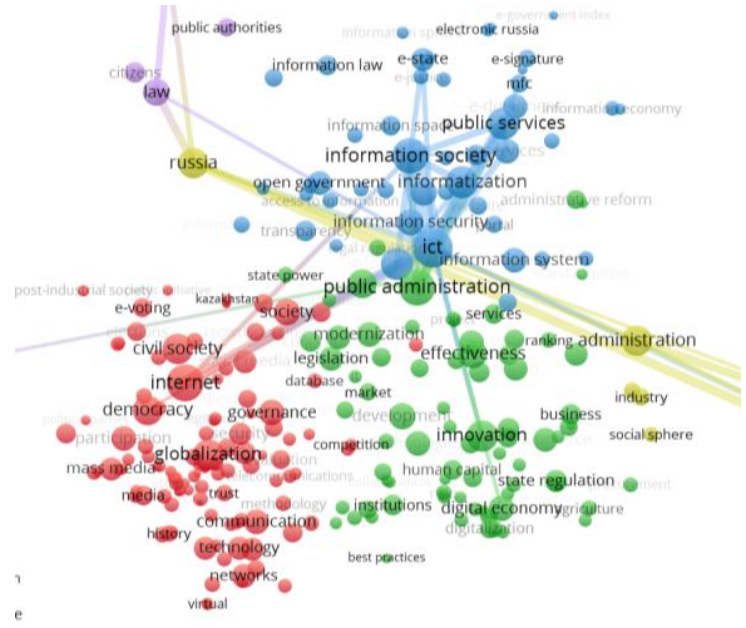

Fig. 3. Co-Occurrence Maps of Keywords in the Russian Agenda. Source: VOSviewer

Our findings echo Erzhenin [10] in that the domain mostly related to social sciences and economy: the balance between hard and soft sciences here is farther skewed towards the latter. Although some trendy concepts are used, the inclusion of new terms is quite reluctant (e.g. e-democracy is still much more frequently used to denote e-participation issues). At the same time, it is prominent for terms with little use outside the country. In other words, the Russian research agenda is lagging behind the international one in conceptual development, as well as the diversity of scope.

The most intuitive explanation for this is the low level of internationalization, which is indeed a usual suspect [6]. The first aspect of this problem is that few scholars from Russia participate in the international research. In the Web of Science sample from section 4 only 123 documents are attributed to the representatives of Russian organizations, with just 96 in English. The majority of documents (71) are conference proceedings papers, and international collaboration is extremely low. This means that the national academic research is to a larger extent developing in isolation from global trends. Yet a more elaborate analysis should be conducted, for example, on the patterns of citation and co-citation in the Russian academia: what international literature "leaks out" to the national research, and to what extent the latter considers it.

The second aspect is the lack of stimuli for the academia to produce knowledge. The global trends in e-government research seem to affect the national agenda only to the extent they reflect the national e-government policy priorities. Thus, Public Services Provision relates to the first attempts of building e-government in Russia via eservices and informatization, while Internet \& Politics (together with "open government") reflects the new period from 2012 onwards, with the attention to public in- 
volvement and the creation of e-participation tools [5]. The most recent development is the digital economy (green cluster), which became a national priority in $2018 .{ }^{1}$

Surely, keeping track of government policy is imperative. However, the absence of other stimuli seem to affect the disciplinary bias towards "softer" attempts to explain and justify policies, from the view of politics, economics management and law. The motivation to address e-government in a more holistic way is limited. Firstly, there is no clear impetus from the industry. The new public management, having become a basis for the Russian administrative reform [18], is still a common practice for government and enterprises. The dominance and reluctance of state corporate business produces a low level of demand for innovations in the country, ${ }^{2}$ and the salience of globally recognized issues (like digital economy, smart cities, big data) is raised by the government itself, in order to wake the academia up. The similar situation persists in more participatory sectors: whereas government initiatives have fostered the interest towards e-participation and open government, low efficacy of such initiatives and non-competitive politics [5] hinder motivation from within.

\section{Discussion}

Although scientometrics is not new to e-government studies, we hope to contribute to the existing literature of that kind in several respects. First of all, we took a holistic view on the research domain, visualized its general structure and highlight the concepts pertinent to various directions of the academic inquiry. The findings confirm the multidisciplinary nature of the domain, with a visible labor among various subfields in knowledge production, and overall balanced representation across hard - soft sciences. Most popular items were also distinguished, thus complementing and confirming earlier findings $[2 ; 4 ; 16]$. At the same time, it questions the interdisciplinarity in e-government research [15; 32], as the clusters are mostly connected via general concepts, though this issue needs further analysis. Our research calls for further collaboration on particular technologies and issues in e-government and e-participation. The presented map might be a guide for such loci of interdisciplinary cooperation.

Secondly, our study complements the research on national research programs [6; 8], by introducing the map of the Russian e-government research. Our findings reverberates the opinion [10] that it differs from the global agenda in scope and depth of inquiry. It is lagging behind the international conceptual and disciplinary development, being dominated. The low internationalization is evident, along with the lack of internal stimuli and demand from business and society to produce innovative and applied research. That raises the need of better cooperation among the Russian and international scholars, as well as collaboration with non-academic actors.

Surely, there are some limitations to this study, as it presents a continuous research project. The use of keyword co-occurrence needs to be complimented by the clustering of concepts from abstracts, and additional software is to be used for advanced network analysis. Some relevant papers might have been missing, not indexed in the

http://government.ru/rugovclassifier/614/events/

https://regnum.ru/news/2228216.html 
Web of Science, or not containing the keywords for which we have searched. There are also some challenges in retrieving bibliometric data from the $e L I B R A R Y$, making it impossible to include other types of bibliometric analysis. We hope that these problems and limitations will be reduced in further research.

\section{Conclusion}

Though scientometrics should not substitute in-depth literature reviews [38], it seems a promising technique of academic and practical value. It allows to explore the conceptual integrity and institutionalization of the research field, and to reveal problems of the national research agenda. We believe this approach can enrich our knowledge of the field, at the same time facilitating its interdisciplinarity, integrity and identity.

As a work in progress, this paper has helped to find new directions of research. We plan to expand the scope by adding new data from alternative bibliometric databases, as well as by retrieving keywords from the abstracts, which help to include more important outlets and research contexts. This can be refined by using additional network analysis techniques to come to more rigorous findings. Also, one of our future research directions is the network analysis of publication sources (journals and conferences) to explore their significance and specialization in e-government research, as well as to reveal patterns of collaboration. It can improve our understanding of the domain from an institutional point of view. Also, since the number of scientometrics techniques and software tools is increasing, it might be an effective way to compare and cross-validate findings achieved. We believe such efforts would contribute to the discussion of the discipline state and perspectives.

\section{Acknowledgement}

The research was supported by the Russian Science Foundation, grant № 18-1800360 'E-participation as Politics and Public Policy Dynamic Factor'

\section{References}

1. Alarabiat A., Soares D.S., Estevez E.: Electronic Participation with a Special Reference to Social Media - A Literature Review. In: Tambouris E. et al. (eds), Electronic Participation. ePart 2016, LNCS in Computer Science, vol 9821, pp. 41-52, Springer, Cham (2016). doi: 10.1007/978-3-319-45074-2_4

2. Alcaide-Muñoz, L., Rodríguez-Bolívar, M. P., Cobo, M. J., \& Herrera-Viedma, E.: Analysing the scientific evolution of e-Government using a science mapping approach. Gov. Inf. Q., 34 (3), 545-555 (2017). doi: 10.1016/j.giq.2017.05.002

3. Bohman, S.: Information Technology in eParticipation Research: A Word Frequency Analysis. In: Tambouris E., Macintosh A., Bannister F. (eds) Electronic Participation. ePart 2014, LNCS, vol 8654, pp. 78-89, Springer, Berlin, Heidelberg (2014). doi: 10.1007/978-3-662-44914-1_7 
4. Cheng, S. Y., Ding, L.: Mapping of Electronic Government: The Trend of Research Fronts. In: 2014 Seventh International Joint Conference on Computational Sciences and Optimization, pp. 509-513, IEEE (2014).

5. Chugunov A.V., Kabanov Y., Zenchenkova K.: Russian e-Petitions Portal: Exploring Regional Variance in Use. In: Tambouris E. et al. (eds) Electronic Participation. ePart 2016. LNCS, vol 9821, pp. 109-122. Springer, Cham (2016). doi: 10.1007/978-3-319-45074-2_9

6. Coelho, T. R., Przeybilovicz, E., Cunha, M. A., \& Echternacht, T. H. S.: Positioning Brazil in International eGov research: a proposal based from literature review. In: 2016 49th Hawaii International Conference on System Sciences (HICSS), pp. 2677-2686, IEEE (2016). doi: 10.1109/HICSS.2016.336

7. de Oliveira Almeida, G., Zouain, D. M., \& Mahecha, Y. L. R.: The Status of EGovernment Research: A Bibliometric Study. Business and Management Review, 3 (11), 7-22 (2014).

8. Dias, G. P.: A decade of Portuguese research in e-government: evolution, current standing, and ways forward. Electronic Government, an Int. J., 12(3), 201-222 (2006).

9. Dwivedi, Y. K.: An analysis of e-Government research published in Transforming Government: People, Process and Policy (TGPPP). Transforming Government: People, Process and Policy, 3(1), 7-15 (2009). doi: 10.1108/17506160910940704

10. Erzhenin, R.V.: Electronic Government: Review of Scientific Publications and Research. Public Administration Issues. 3, 205 - 228 (2018) [in Russian]

11. Fonou Dombeu, J. V., \& Rannyai, N.: African e-government research landscape. The African J. of Inf. Sys., 6 (3), $85-119$ (2014).

12. Grönlund, Å.: State of the Art in e-Gov Research - A Survey. In: Traunmüller R. (eds) Electronic Government, EGOV 2004, LNCS, vol 3183, pp. 178-185, Springer, Berlin, Heidelberg (2004). doi: 10.1007/978-3-540-30078-6_30

13. Hassan, L., \& Hamari, J.: Gamification of E-Participation: A Literature Review. In: Proceedings of the 52nd Hawaii International Conference on System Sciences (2019). URL: http://hdl.handle.net/10125/59744

14. Heeks, R., \& Bailur, S.: Analyzing e-government research: Perspectives, philosophies, theories, methods, and practice. Gov. Inf. Q, 24(2), 243-265 (2007). doi: 10.1016/j.giq.2006.06.005

15. Hwang, S., \& Murphy, P.: Mapping out e-government research literature: How interdisciplinary was it for the blooming decades?. Electronic Government, an Int. J., 13(3), 224241 (2017). doi: 10.1504/EG.2017.086684

16. Jafarjalali, S. M.: Visualizing e-government emerging and fading themes using SNA techniques. In: 2016 10th International Conference on e-Commerce in Developing Countries: with focus on e-Tourism (ECDC), IEEE (2016). doi: 10.1109/ECDC.2016.7492983

17. Khan, G. F., \& Park, H. W.: The e-government research domain: A triple helix network analysis of collaboration at the regional, country, and institutional levels. Gov. Inf. Q., 30(2), 182-193 (2013). doi: 10.1016/j.giq.2012.09.003

18. Klimenko, A.V.: A Decade of Administrative Reform: Results and New Challenges. Public Administration Issues, 1, 8-51 (2014). [in Russian]

19. Lutz, C., Hoffmann, C. P., \& Meckel, M.: Beyond just politics: A systematic literature review of online participation. First Monday, 19(7), 1-36 (2014). doi: 10.5210/fm.v19i7

20. Macintosh, A.: E-Democracy and E-Participation Research in Europe. In: Chen H. et al. (eds) Digital Government. Integrated Series In Information Systems, vol 17., pp. 85-102, Springer, Boston, MA (2008). doi: 10.1007/978-0-387-71611-4_5

21. Medaglia, R.: eParticipation research: Moving characterization forward (2006-2011). Gov. Inf. Q., 29(3), 346-360 (2012). doi: 10.1016/j.giq.2012.02.010 
22. Meijer, A., \& Bolívar, M. P. R.: Governing the smart city: a review of the literature on smart urban governance. Int. Rev. of Adm. Sciences, 82(2), 392-408 (2016). doi: $10.1177 / 0020852314564308$

23. Meijer, A., Bekkers, V.: A Metatheory of E-Government: Creating Some Order in a Fragmented Research Field. Gov. Inf. Q. 32 (3), 237 - 245 (2015). doi: 10.1016/j.giq.2015.04.006

24. Qi, T., Wang, T., Ma, Y., Zhang, W., \& Zhu, Y.: A scientometric analysis of eparticipation research. International Journal of Crowd Science, 2(2), 136-148 (2018). doi: 10.1108/IJCS-08-2018-0015

25. Reece, B.: E-government literature review. Journal of E-government, 3(1), 69-110 (2006). doi: 10.1300/J399v03n01_05

26. Ridley, G.: EGovernment: Making Sense of Fragmentation and Contradiction. In: E-gov pre-ECIS Workshop, 8th June 2008, Galway Ireland (2008). URL: https://eprints.utas.edu.au/7062/

27. Rodríguez-Bolívar, M. P., Alcaide-Muñoz, L., \& Cobo, M. J.: Analyzing the scientific evolution and impact of e-Participation research in JCR journals using science mapping. Int. J. of Information Management, 40, 111-119 (2018). doi: 10.1016/j.ijinfomgt.2017.12.011

28. Sæbø, Ø., Rose, J., \& Flak, L. S.: The shape of eParticipation: Characterizing an emerging research area. Gov. Inf. Q, 25(3), 400-428 (2008). doi: 10.1016/j.giq.2007.04.007

29. Scherer, S., \& Wimmer, M. A.: Trust in e-participation: Literature review and emerging research needs. In: Proceedings of the 8th International Conference on Theory and Practice of Electronic Governance, ICEGOV, pp. 61-70, ACM (2014). doi: 10.1145/2691195.2691237

30. Scholl H.J.: Electronic Government Research: Topical Directions and Preferences. In: Wimmer M.A. et. al (eds) Electronic Government, EGOV 2013, LNCS, vol. 8074, pp. 113, Springer, Berlin, Heidelberg (2013). doi: 10.1007/978-3-642-40358-3_1

31. Scholl, H. J. J., \& Dwivedi, Y. K.: Forums for electronic government scholars: Insights from a 2012/2013 study. Gov. Inf. Q., 31(2), 229-242 (2014). doi: 10.1016/j.giq.2013.10.008

32. Scholl, H. J. J.: Discipline or Interdisciplinary Study Domain? Challenges and Promises in Electronic Government Research. In: Digital Government, Integrated Series In Information Systems, vol 17, Springer, Boston, MA, pp. 21-41 (2008). doi: 10.1007/978-0-387-716114_2

33. Susha, I., \& Grönlund, Å.: eParticipation research: Systematizing the field. Gov. Inf. Q., 29(3), 373-382 (2012). doi: 10.1016/j.giq.2011.11.005

34. Van Eck, N. J. V., \& Waltman, L.: How to normalize cooccurrence data? An analysis of some well-known similarity measures. Journal of the American society for information science and technology, 60(8), 1635-1651 (2009). doi: 10.1002/asi.21075

35. Van Eck, N. J., Waltman, L., Dekker, R., \& van den Berg, J.: A comparison of two techniques for bibliometric mapping: Multidimensional scaling and VOS. J. of the American Society for Inf. Sc. and Tech., 61(12), 2405-2416 (2010). doi: 10.1002/asi.21421

36. Van Eck, N.J., \& Waltman, L.: Software survey: VOSviewer, a computer program for bibliometric mapping. Scientometrics, 84(2), 523-538 (2010). doi: 10.1007/s11192-009-01463

37. Yildiz, M.: E-government research: Reviewing the literature, limitations, and ways forward. Gov. Inf. Q, 24(3), 646-665 (2007). doi: 10.1016/j.giq.2007.01.00

38. Zupic, I., \& Čater, T.: Bibliometric methods in management and organization. Organizational Research Methods, 18(3), 429-472 (2015). doi: 10.1177/1094428114562629 